\title{
Energy Simulation of Buildings with a Modular Object-Oriented Tool
}

\author{
Rashmin Damle ${ }^{1}$, Oriol Lehmkuhl ${ }^{1,2}$, Guillem Colomer $^{1}$, and Ivette Rodriguéz ${ }^{2}$ \\ ${ }^{1}$ TermoFluids,S.L., Magí Colet 8, 08204, Sabadell, Barcelona (Spain) \\ 2 Centre Tecnològic de Transferència de Calor (CTTC), \\ Universitat Politècnica De Catalunya, Colom 11, 08222 Terrassa (Barcelona), Spain
}

\begin{abstract}
The aim of this work is to develop a modular object-oriented tool "NEST" (Numerical Edifice Simulation Tool) for the energy simulation of buildings, which can be coupled with a parallel CFD software. For this purpose, a building is modelled as a collection of basic elements (walls, rooms, outdoor, openings, etc.). Different models (1D, 2D, simplified energy balances, CFD \& HT, etc) are implemented for different elements which are capable of solving themselves for given boundary conditions. The elements can be linked to each other to form a specific building configuration. Thus new configurations can be quickly formed by adding or removing the required elements. Such an approach gives flexibility of choosing a model for each element and to have different levels of modelling for different elements in the system. Moreover, elements developed can be used for applications not restricted to buildings only. The object-oriented methodology, element descriptions, BESTEST cases for code validation, and transient thermal simulations of two different cases are presented in this paper.
\end{abstract}

\section{Introduction}

This work is addressed to contribute to the progress in the numerical simulation of the thermal and fluid flow processes within and around buildings. Building energy consumption has increased from $20 \%$ to $40 \%$ in developed countries, and the HVAC (Heating Ventilating and Air-Conditioning) systems account for almost half the energy consumed in buildings (Pérez-Lombard, et al. 2008). Energy simulation of buildings is critical for optimizing the energy demands as building thermal systems are major consumers of energy as far as their construction, operation and maintenance is concerned. It can give vital information of the peak loads during the heating and cooling season, room temperatures and velocity distributions for maintaining an adequate indoor environment, and overall energy demands during an year. This information can be used at the design stage to reduce the energy costs with a good architectural and HVAC design.

Buildings can be considered as thermal systems interacting with the surroundings through heat transfer and fluid flow processes. A numerical approach to handle the heat transfer and fluid flow in such systems not only helps in saving the full scale experiment time and cost, but also helps in optimizing the governing parameters for the efficient functioning of the entire system. The prediction of the physical phenomena involved in buildings is difficult due to the large and complex geometry involved, changing boundary conditions, airflows due to natural convection, stack and wind effects, infiltration of ambient air and mechanical ventilation, and the mixture of free and forced convection flows which are often are turbulent.

Numerical simulations imply mathematical modeling of the different physical processes occurring in a building thermal system. The models implemented could be simple zero dimensional expressions, one dimensional models based upon experimental correlations, two or three dimensional analysis with turbulence models or direct numerical simulations (DNS) for detailed resolution of fluid flow and heat transfer, etc. The level of modelling a given process may be different depending upon the nature of the process, resources, and the accuracy desired.

Numerous building energy simulation programs have been developed over the years. MODSIM (Sahlin, 1988), EKS (Clarke, et al. 1992), SPARK (Buhl, et al. 1993) are some of the earlier objected oriented initiatives for modular simulation. CONTAM (Walton and Dols, 2005) is a multizone model which has been used to calculate the indoor air quality in buildings. COMIS (Feustel, 1999) is a multizone model prepared 
by experts of the IEA (International Energy Agency) and is used widely in USA. Moreover, the coupling of CFD with building simulations has been addressed by several authors. One of the earlier attempts of CFD integration with building simulations was presented by Negrao (1998). Musser (2001) and Zhai \& Chen (2003) also did studies in this direction. More recently, Wang and Chen (2007) studied three possibilities of coupling methods between CFD and multizone network program. An overview of twenty major simulation programs (e.g., BLAST, TRNSYS, etc.) and their capabilities was presented by Crawley, et al. (2008), and an overview of methods for ventilation performance can be found in Chen (2009).

The objective of this work is towards the development of a modular object-oriented building simulation tool, including coupling between low level resolution models with CFD models based on large eddy simulation (LES) models, with special attention to the parallelization of the simulation with numerous processors. Thus, it represents a new attempt to represent all these features in a single tool. This is especially necessary if, as mentioned earlier, some critical processes/zones need to be modelled with more detail than others. For example, wall and ground heat transfer resolution in two or three dimensions, or a large eddy simulation for the resolution of Navier-Stokes equations in some of the zones where more information is needed about the temperature and velocity distributions. This will need many processors for the simulation to be feasible in reasonable time. In this context, a modular object-oriented methodology can be very useful for the simulation of building processes with diferent level of modelling for different zones/processes and finally couple it with the parallel CFD software TermoFluids (Lehmkuhl, et al. 2007). The modular methodology, description of the elements developed, the global resolution algorithm of the NEST tool, and BESTEST cases (Judkoff and Neymark, 1995) for code validation are presented in the following sections. Finally, two illustrative case studies (a building and a wind turbine nacelle), as different applications, are also worked out using the same basic elements.

\section{Modular Approach}

In this paper, a building or a structure is modelled as a collection of basic elements (walls, rooms, windows, outdoor, etc.) as shown in the Figure 1a and Figure 1b.

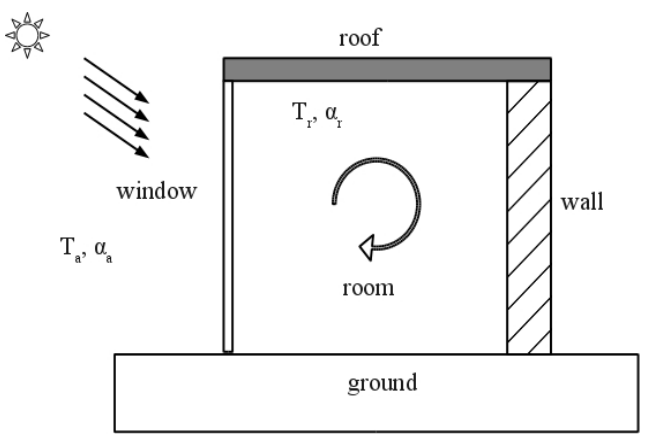

Figure 1a: A simple building.

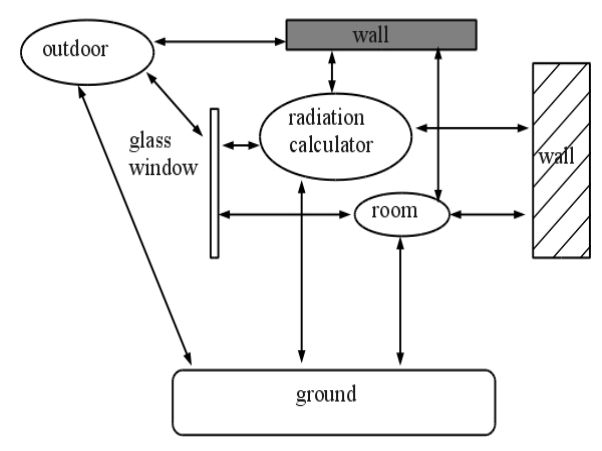

Figure 1b: The building as a collection of elements.

Thus, a given configuration of a building (a thermal system) is then made by linking the different elements as needed. A summary of the different elements (objects from $\mathrm{C}++$ programming point of view) which constitute NEST are given in Table 1. These objects are capable of solving themselves when subjected to boundary conditions which are taken from the neighbouring elements.

At each iteration, inputs (e.g., pressure, temperature, etc.) are taken from the neighbours, governing equations of the element are solved and the outputs (e.g., pressure, temperature, etc.) are set as boundary conditions for the resolution of the neighbour elements. Iterations continue until convergence is reached at a 
Table 1. Summary of the elements (objects) developed for NEST.

\begin{tabular}{|l|l|}
\hline Elements & Description \\
\hline Calendar & Keeps time in two different modes. \\
\hline Global Position & Stores the geographical position (latitude, longitude, etc.). \\
\hline Local Position & Stores the orientation and local position of exterior walls. \\
\hline Outdoor & Read/calculates outdoor data like temperature, wind, solar radiation, etc. \\
\hline Time function & Retrieves/interpolates values of variables at a given time. \\
\hline Ground & Resolves three dimensional heat conduction and surface convection. \\
\hline Wall & $\begin{array}{l}\text { Single material layer with one dimensional heat conduction, moisture transport, } \\
\text { and heat convection, thermal radiation and solar gains at surfaces. }\end{array}$ \\
\hline Composite wall & $\begin{array}{l}\text { Multiple material layers with one dimensional heat conduction, } \text { moisture } \\
\text { transport, and heat convection, thermal radiation and solar gains at surfaces. }\end{array}$ \\
\hline Glass wall/window & $\begin{array}{l}\text { Glass layer transparent to solar radiation with one dimensional heat conduction, } \\
\text { and heat convection and radiation at surfaces. }\end{array}$ \\
\hline Room & One node control volume with mass, moisture and energy balance. \\
\hline Radiation calculator & Calculates view factors for thermal radiation calculation. \\
\hline Solar distributor & Distributes the transmitted solar radiation uniformly to room walls. \\
\hline Air change calculator & Calculates air infiltration. \\
\hline HVAC & Controls heating and cooling of rooms. \\
\hline Opening & Air movement between rooms and outdoor due to pressure differences. \\
\hline Door & Air movement between rooms connected with large openings \\
\hline Internal volumes & Volumes with surfaces at a given temperature or with heat flux \\
\hline Flow network & $\begin{array}{l}\text { Calculates the flows across a network of rooms with a Newton-Raphson } \\
\text { method by taking into account the mass residuals of the entire network. }\end{array}$ \\
\hline CFD object & $\begin{array}{l}\text { Detailed three dimensional resolution of fluid flow and heat transfer with or } \\
\text { without turbulence models }\end{array}$ \\
\hline
\end{tabular}

given time step and then the next time step calculation starts after updating the variables. The global resolution algorithm is shown in Figure 2. The algorithm works like a Gauss-Seidel method passing through

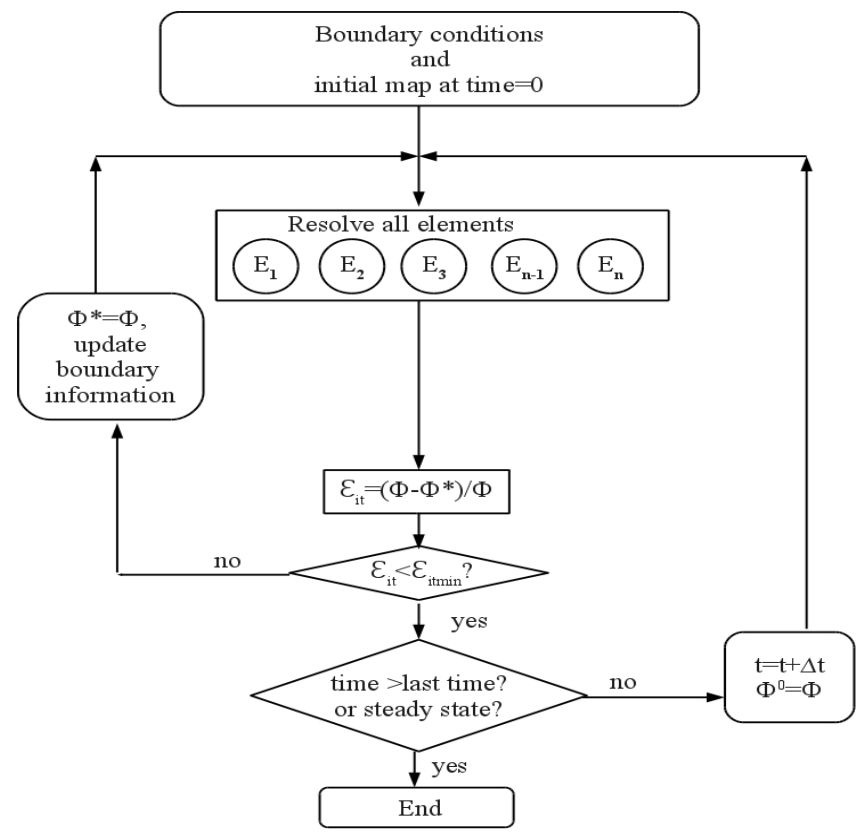

Figure 2: Global resolution algorithm. 
all elements and updating the values. However, the flow network object evaluates the pressure correction values for all rooms taking into account the mass residuals of all the connected rooms with the NewtonRaphson method. This leads to faster convergence of the airflow network between zones. The advantage of such a modular approach, as can be seen from Figure 1 and Figure 2, is that each element can be represented in any form as long as it can exchange the necessary boundary information from the rest of the elements in the system. For instance, in a building with many rooms, some rooms can be modelled with a detailed CFD \& HT calculation while other rooms could be modelled using a single node energy balance. Also, new element models can be easily implemented without changing basic the program structure.

\section{Code Validation}

\subsection{Basic thermal balances and feasibility of the program}

The objects or individual elements, described until now, form a thermal system when linked together according to the type of building configuration. The working of all the objects has been verified by simulating cases like: i) Wall/composite wall/glass wall objects exposed to outdoor with convection and radiation at surfaces; ii) A cube shaped house with six walls (wall and transparent glass wall objects), a uniform temperature room object connected with the walls for convection, a radiation calculator for thermal radiation with external walls connected to the outdoor object (outdoor data from commercial software METEONORM, 1994); iii) The view factors calculated by the radiation calculator object were compared with the view factors for known geometries; iv) Method of manufactured solutions was used for the ground object to verify three dimensional heat conduction along with heat convection at the top surface. Energy balances for all the cases were ensured at each time step along with physically realistic results.

A program was also created to test the feasibility of the solution algorithm when a large number of elements are connected to form a building. The program, when given the coordinates of the vertices of a parallelopiped, constructs a building with $\mathrm{i} \times \mathrm{j} x \mathrm{k}$ rooms with walls, rooms, radiation calculators and the outdoor objec. For example, when given the coordinates of the vertices of a cube of side 15 metres and $\mathrm{i}=\mathrm{j}=\mathrm{k}=5$, a building with 125 rooms $(5 \times 5 \times 5)$ each of dimension $3 \mathrm{~m} \times 3 \mathrm{~m} \times 3 \mathrm{~m}$ is created with walls, radiation boxes and rooms. The exterior surfaces are then linked to the outdoor object. Cases with $2 \times 2 \times 2,3 \times 3 \times 3$, $4 \times 4 \times 4$ and $5 \times 5 \times 5$ rooms were simulated to see the transient behaviour with time step of the order of 900 seconds.

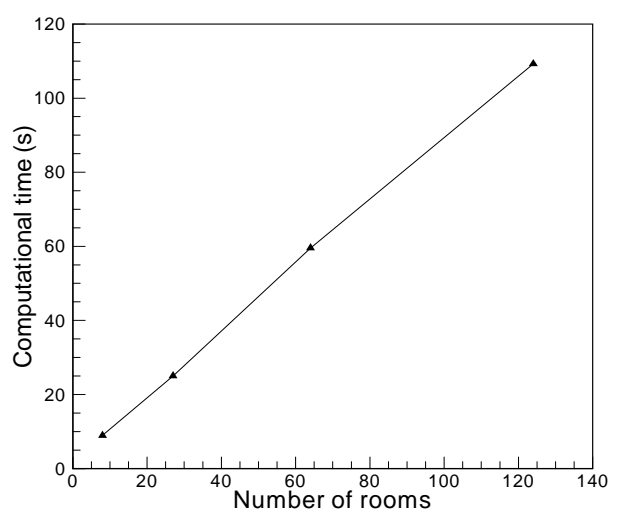

Figure 3: Computational time variation with the number of rooms.

The ambient temperature changes gradually over the length of the day and therefore the number of iterations at each time step (around 25 iterations) is lesser to cover these gradual changes. The computational time for a given time step with the number of rooms is shown in Figure 3. It can be seen that the time required increases linearly and thus, the solution algorithm can be employed for large number of elements connected in a thermal system. 


\subsection{Comparison of NEST with BESTEST cases}

Apart from the basic tests mentioned above, BESTEST qualification cases (600 and 900) published by Judkoff and Neymark (1995) were simulated in the free-floating mode for program validation. Figure 4 and Figure 5 show the hourly values of indoor temperature calculated by NEST for $4^{\text {th }}$ of January for lightweight and heavyweight building structures respectively. It can be seen that the values agree reasonably well with other building simulation programs.

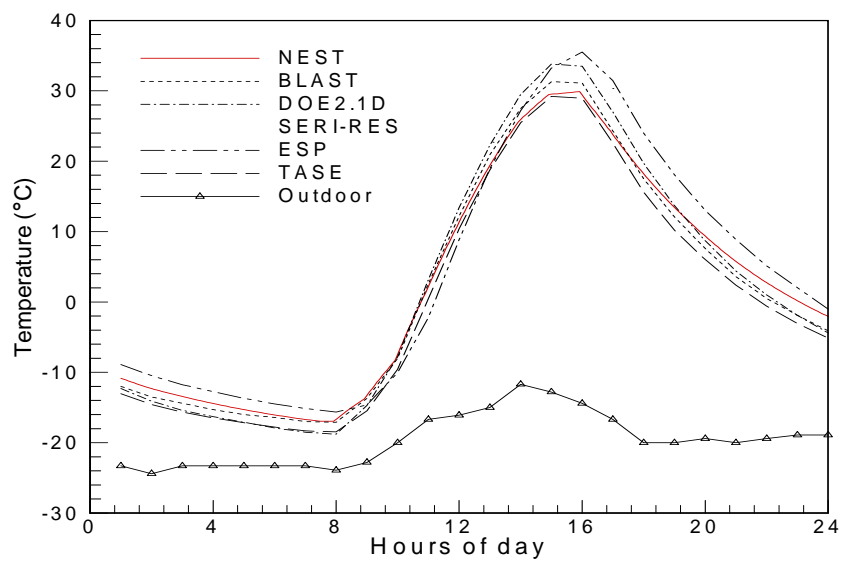

Figure 4: Indoor temperature variation on $4^{\text {th }}$ January for a lightweight structure.

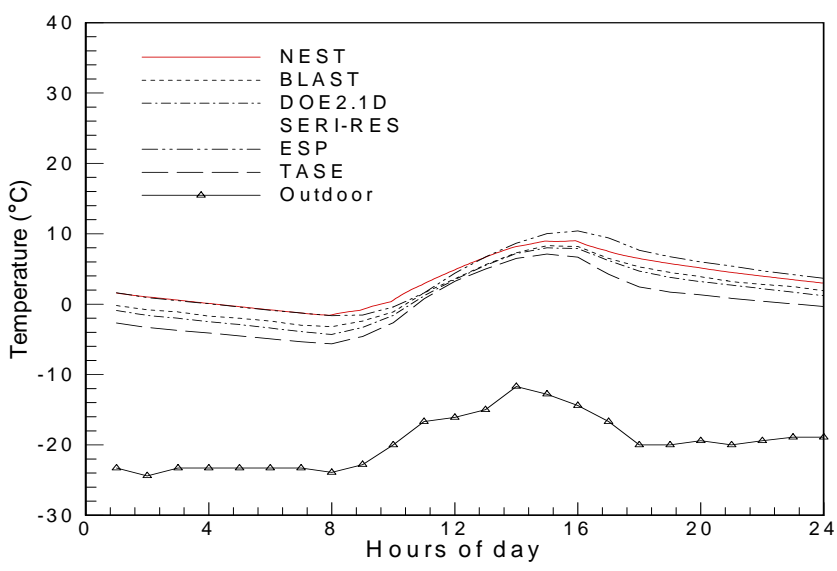

Figure 5: Indoor temperature variation on $4^{\text {th }}$ January for a heavyweight structure. 


\subsection{Mixed convection case for the validation of the CFD object}

In this section a mixed convection airflow in a three dimensional cavity is considered for the validation of TermoFluids (Lehmkuhl et al., 2007) code. This code will be used further for simulating room air in the CFD object for building applications. The schematic of the test case is shown in the Figure 6.

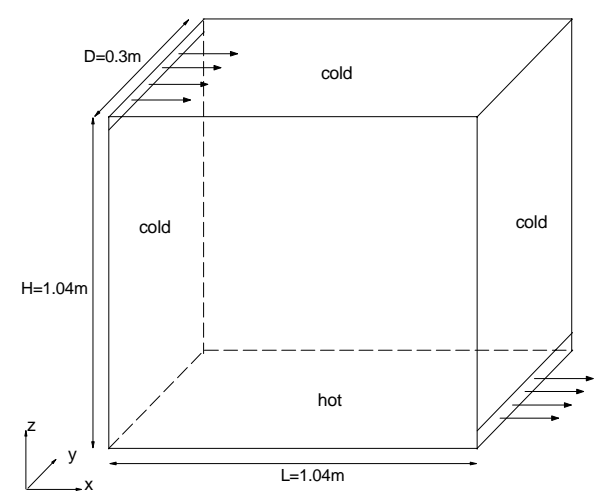

Figure 6: Schematic of the experimental setup.

The experimental data for this case has been published by Blay, et al. (1992). Also, this case, which is a representative of the airflow in building, has been studied by Mergui (1993), Zhang and Chen (2000) and Ezzouhri, et al. (2009). The length $(\mathrm{L})$ and the height $(\mathrm{H})$ of the cavity are $1.04 \mathrm{~m}$, and the depth $(\mathrm{D})$ of the cavity is $0.3 \mathrm{~m}$. Air enters the cavity top at $15^{\circ} \mathrm{C}$ with a mean inlet velocity of $0.57 \mathrm{~m} / \mathrm{s}$ through a slot of height $h=0.018 \mathrm{~m}$ along the depth of the cavity, and leaves through a similar slot of height $l=0.024 \mathrm{~m}$ at the bottom of opposite wall. The bottom surface of the cavity is at $35^{\circ} \mathrm{C}$ while the top and the lateral walls are at $15^{\circ} \mathrm{C}$. The front and the rear walls are adiabatic. The Rayleigh number for this case is $2.23 \times 10^{9}$, while the Reynolds number and the Archimedes number are 684 and 0.036 respectively. A parabolic inlet velocity distribution is imposed according to the measured velocity profile (Ezzouhri, et al. 2009).

A mesh with 100x120x32 control volumes has been used for the simulation of this case with 104 processors with an integration time of 500 seconds. Yoshizawa Smagorinsky LES model (Yoshizawa, et al. 2000) is used for the simulation of this case. Numerically obtained mean velocities are compared with the experimental data by Blay, et al. (1992) in Figure 7a and Figure 7b. It can be seen that the numerical and experimental values of the mean horizontal and mean vertical velocities are in good agreement, and the TermoFluids (Lehmkuhl, et al. 2007) code is able to reproduce the physics of the flow to a good extent.

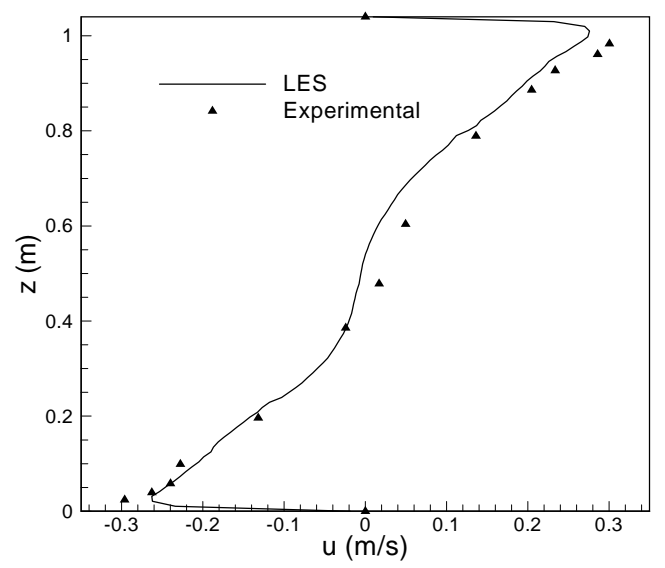

Figure 7a: Mean horizontal velocity (u) with $\mathrm{z}$ at $y=0.15 \mathrm{~m}$ and $\mathrm{x}=0.52 \mathrm{~m}$.

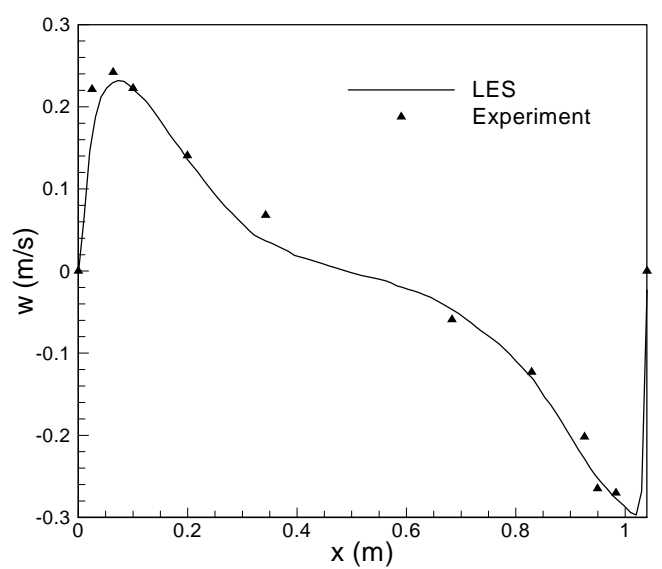

Figure 7b: Mean vertical velocity (w) with $\mathrm{x}$ at $\mathrm{y}=0.15 \mathrm{~m}$ and $\mathrm{z}=\mathbf{0 . 5 2 \mathrm { m }}$. 


\section{Case Studies}

In this section transient simulations under varying ambient conditions, performed for a single family house and a wind turbine nacelle, are presented. Both the configurations are formed with the basic elements aforementioned.

\subsection{Thermal simulation of a house}

A single family house with dimensions $8.4 \mathrm{~m}$ x $13.8 \mathrm{~m}$ x $3.5 \mathrm{~m}$ ( 8 zones) was formed by linking elements like walls, composite walls, glass walls, rooms, radiation calculators, outdoor, etc. and simulated in a transient mode. Different types of wall materials were employed for external walls to see their behaviour and to use thermal inertia for reducing the heating and cooling costs during the year. For brevity, results are given only for the month of May when the days are hot and the nights are cold. The geographical location is of the the place Zaragoza (Spain). The infiltration rate is calculated by the air change calculator object using the LBL (ASHRAE, 1991) model with the leakage areas for the house components calculated according to Keider and Rabl (1994). HVAC object controls the temperature of the different rooms by switching on and off the heating and cooling devices. The house floor is a $30 \mathrm{~cm}$ thick concrete layer forming the uppermost central part of the ground object. The ground extends $10 \mathrm{~m}$ deep below the concrete layer and $12 \mathrm{~m}$ sideways in all directions. The open surfaces of the ground are connected to the outdoor object for receiving solar radiation and ambient parameters like temperature and velocity.

The different types of exterior walls considered here are: i) Type A (prefabricated panels with $4.86 \mathrm{~cm}$ of polyurethane layer between $0.7 \mathrm{~mm}$ steel sheets); ii) Type B (20 cm common brick); iii) Type C (5cm of polyurethane layer between bricks of $12 \mathrm{~cm}$ thickness). The overall heat transfer coefficient $\left(\mathrm{U}\left(\mathrm{W} / \mathrm{m}^{2} \mathrm{~K}\right)\right)$ for types A, B and C is approximately $0.48,1.37$ and 0.40 respectively. The passive behaviour of the external walls the house is simulated with heating and cooling switched off. Figure 8a and Figure 8b show the evolution of the wall and room temperatures for the month of May for the prefabricated wall and the brick wall respectively.

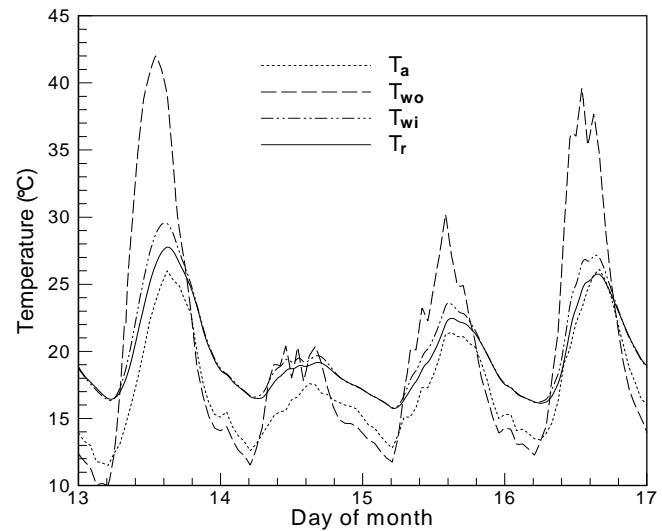

Figure 8a: Temperature evolution with days for the prefabricated wall (type A).

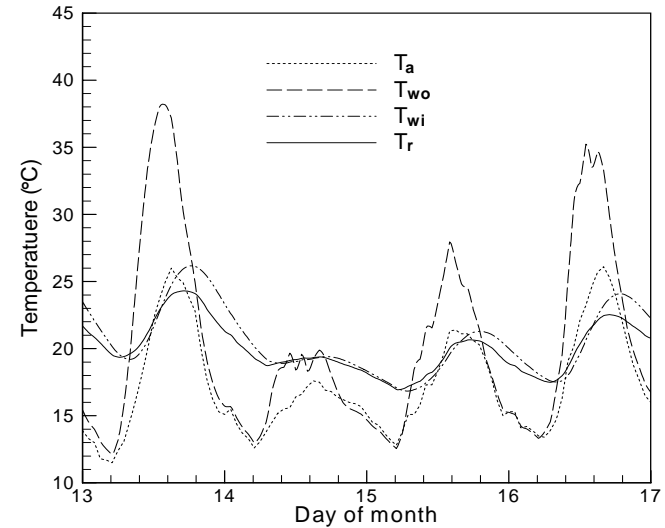

Figure 8b: Temperature evolution with days for the brick wall (type B).

It can be observed that in case of the brick wall (with higher U-value) the room temperature curve has lesser fluctuations as compared to the prefabricated case. Also, the temperature changes are more gradual for the brick wall and there is a time lag between the peaks of the ambient temperature $\left(\mathrm{T}_{\mathrm{amb}}\right)$ and the room temperature $\left(T_{r}\right)$. This is because of the thermal inertia of the brick wall which resists the changes in the ambient temperature to a greater extent than the prefabricated wall. Moreover, the room temperature goes above $27^{\circ} \mathrm{C}$ in the case of the prefabricated wall (see Figure 8a) unlike the brick wall where the room temperature is below $25^{\circ} \mathrm{C}$ for most of the time as shown in the Figure $8 \mathrm{~b}$. This would result in reduction of the cooling load. Similarly, during the nighttime the room temperature falls below $17^{\circ} \mathrm{C}$ in the case of the prefabricated wall while the brick wall keeps the room warmer leading to reduction in the heating load. Thus, 
the thermal inertia plays an important role for the periods of the year with larger variation in the diurnal temperatures and if used properly could lead to substantial savings in the energy costs.

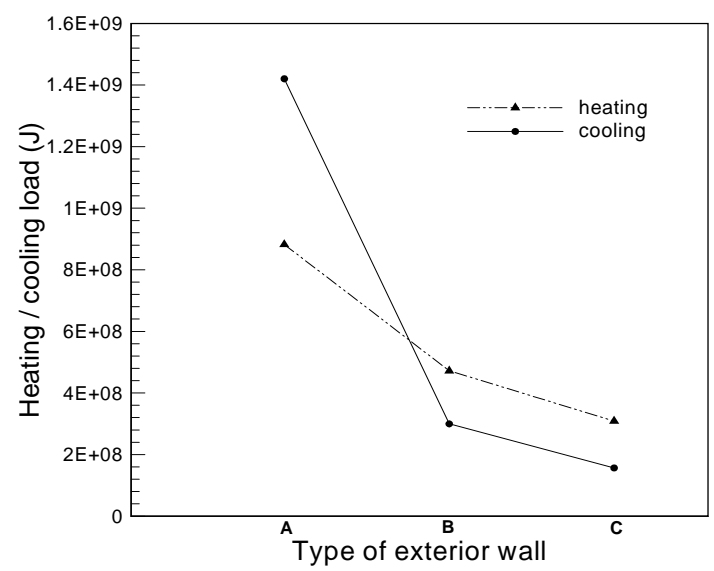

Figure 9: Heating and cooling loads for the month of May.

Figure 9 shows the heating or cooling loads for the different wall types used in this study. Exterior wall made of brick alone (type B) can cause $46 \%$ reduction in the heating load and $78 \%$ reduction in the cooling load. Putting insulation between the brick layers (type C) leads to $65 \%$ and $89 \%$ reduction in heating and cooling loads respectively. Thus, analysis can be made with different materials to see their effect on the room conditions.

\subsection{Thermal simulation of the nacelle of a wind turbine}

A preliminary illustrative transient thermal simulation of the nacelle of a wind turbine was also done with elements like room, outdoor, openings (inlets, outlets), and internal volumes with heat generation or at constant temperature. The nacelle was modelled as a three zone envelope as shown in the Figure 10. The central zone 1 is connected to the zone 2 as well as zone 3 with openings which are modelled as a door object and an opening object respectively. Also, there are openings through which the ambient air enters the central zone $1\left(\mathrm{In}_{1}\right)$ and leaves zone $3\left(\mathrm{Out}_{1}\right)$. The different parts within the nacelle, e.g., the generator, the gearbox, the equipment box and the transformer were put as internal volumes with heat dissipation or at a specified temperature.

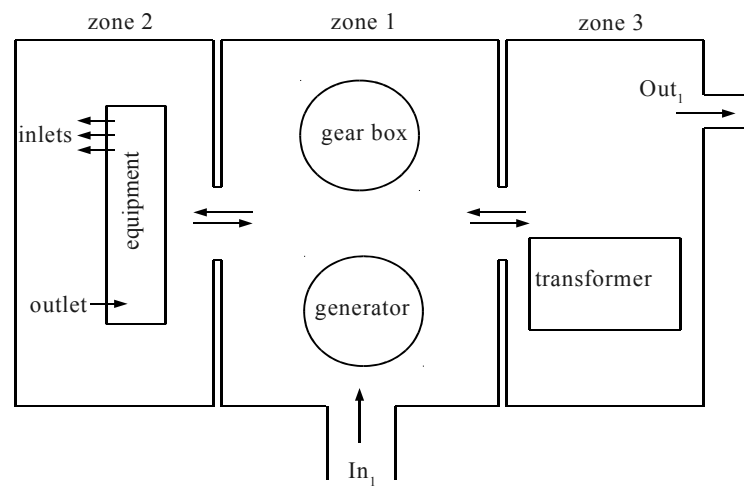

Figure 10: Schematic of the nacelle.

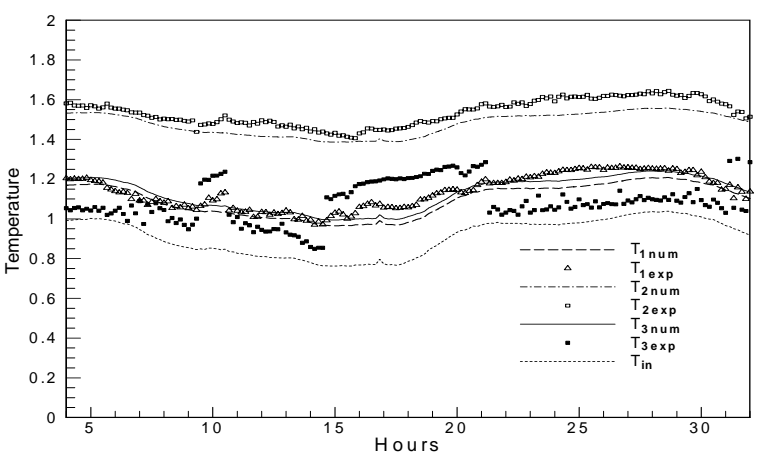

Figure 11: Temperature variation of different zones with time.

The values of the heat dissipated by the transformer and the surface temperatures of the gearbox, the equipment box and the generator were supplied from the measured data as a function of operating conditions and time. The nacelle orientation changes with the wind direction and therefore its orientation with respect to 
the sun for the incident solar radiation. Figure 11 shows the numerical values of the average temperature plotted against the experimental temperature values for each zone, which are non-dimensionalized with a reference temperature of $30^{\circ} \mathrm{C}$. The predicted temperatures for zone 1 and zone 2 agree quite well with the measured values during the day and night cycle, and the zone 3 temperature curve passes between the corresponding measured data. Even with a simple mass and energy balance of the nacelle zones with varying outdoor conditions (e.g., wind speed, solar radiation, temperature, etc.), the numerical simulation captures the trends of the experimental observations. The results are encouraging for the relatively simple model used. In the future studies, the element models will be improved and CFD \& HT analysis of some zones will be done.

\section{Conclusions and future work}

A modular object-oriented tool "NEST" has been developed for the transient thermal and fluid simulation of buildings for coupling it with parallel CFD software TermoFluids (Lehmkuhl, et al. 2007). A building, as a thermal system, is modelled as a collection of basic elements like walls, rooms, openings, outdoor, etc. These elements are programmed only once in a general way and only interact through boundary conditions. There is no need to program specific system configurations as a whole. Instead, different configurations are made by linking the same basic elements. New element models can be easily incorporated which leads to time savings and adds flexibility to the software. Feasibility tests show that the simulation time increases linearly with the number of elements, and thus a large number of elements can be simulated with acceptable computational time. Also, the program has been validated with BESTEST cases 600 and 900 (Judkoff and Neymark, 1995) which ensure satisfactory working of NEST. In the future, more tests will be conducted to assure higher quality of the simulations.

Thermal simulation of a single family house with different wall materials shows the effect of different wall types on the heating and cooling loads and the role of thermal inertia. Energy demands and the peak loads during the year can be calculated and studies can be made by using different materials/elements in the building construction. Finally, a preliminary numerical simulation of a wind turbine nacelle formed with the same basic elements is presented to show the advantage of the methodology presented in other applications. Considering the relatively simple model employed in this case, the numerically calculated zonal temperatures show similar trends when compared with the measured values and agree fairly during various parts of the day and night cycle. The individual element models will be improved in the future (e.g., moisture in walls, coarse mesh models for room air, etc.) and new elements will be added.

\section{References}

1. ASHRAE, 1989. Handbook of Fundamentals. Atlanta.

2. Blay, D., Mergui, S., Nicolae, C., 1992. Confined turbulent mixed convection in the presence of horizontal buoyant wall jet. Fundamentals of Mixed Convection. 213, 65-72.

3. Buhl, W.F., Erdem, A.E., Winkelmann, F.C., Sowell, E.F., 1993. Recent Improvements in SPARK: Strong Component Decomposition, Multivalued Objects, and Graphical Interface. Building Simulation '93, Adelaide, International Building Performance Simulation Association. pp. 283-289.

4. Chen, Q., 2009. Ventilation performance prediction for buildings: A method overview and recent applications. Building and Environment. 44, 848-858.

5. Clarke, J., Tang. D., James, K., 1992. The Energy Kernel System, Final Report for Grant GR/F/07880, submitted to the SERC, ESRU, Department of Mechanical Engineering, University of Strathclyde.

6. Crawley, D.B., Hand, J.W., Kummert, M., Griffith, B.T., 2008. Contrasting the capabilities of building energy performance simulation programs. Building and Environment. 43, 661-673.

7. Ezzouhri, R., Joubert, P., Penot, F., Mergui, S., 2009. Large eddy simulation of turbulent convection in a 3D ventilated cavity: comparison with existing data. International Journal of Thermal Sciences. 48, 2017-2024. 
8. Feustel, H.E., 1999. COMIS - an international multizone air-flow and contaminant transport model. Energy and Buildings. 30, 3-18.

9. Judkoff, R., Neymark, J., 1995. Building energy simulation test (BESTEST) and diagnostic method, NREL/TP-472-6231. Golden, Colorado 80401-3393: National Renewable Energy Laboratory.

10. Kreider, J.F., Rabl, A., 1994. Heating and Cooling of Buildings: design for efficiency, McGraw-Hill book company.

11. Lehmkuhl, O., Borrell, R., Pérez-Segarra, C.D., Soria, M., Oliva, A., 2007. A new parallel unstructured CFD code for the simulation of turbulent industrial problems on low cost PC Cluster, Proceedings of PCFD, Turkey.

12. Mergui, S., 1993. Caracterisation experimentale des ecoulements d'air de convection naturelle et mixte dans une cavite fermee, Thèse de l'Universite de Poitiers, France.

13. METEONROM 4.0, 1999. Meteotest Fabrikstrasse 14, CH-3012 Bern, Switzerland.

14. Musser, A., 2001. An analysis of combined CFD and multizone IAQ model assembly issues. ASHRAE Transactions. 107, 371-382.

15. Negrao, C.O.R., 1998. Integration of computational fluid dynamics with building thermal and mass flow simulation, Energy and Buildings, 27 (2), pp. 155-165.

16. Pérez-Lombard, L., Ortiz, J., Pout, C., 2008. A review on buildings energy consumption information. Energy and Buildings. 40, 394-398.

17. Sahlin, P., 1988. MODSIM - a program for dynamic modelling and simulation of continuous systems, The Swedish Institute of Mathematics.

18. Yoshizawa, A., Kobayashi, K., Kobayashi, T., Taniguchi, N., 2000. A non-equilibrium fixed parameter subgrid scale model obeying the near wall asymptotic constraint. Physics of Fluids. 12(9), 2338-2344.

19. Walton, G.N., Dols, A.S., 2005. CONTAM 2.4b, User Guide and Program Documentation Building Environment Division Building and Fire Research Laboratory, NIST, Gaithersburg, MD 20899-8633.

20. Wang, L., Chen, Q., 2007. Theoretical and numerical studies of coupling multizone and CFD models for building air distribution simulations. Indoor Air. 17, 348-361.

21. Zhai, Z., Chen, Q., 2003. Solution characters of iterative coupling between energy simulation and CFD programs. Energy and Buildings. 35, 493-505.

22. Zhang, W., Chen, Q., 2000. Large eddy simulation of indoor air flow with a filtered dynamic subgrid scale model. International Journal of Heat and Mass transfer. 43, 3219-3231.

\section{Nomenclature}

CFD \& HT: computational fluid dynamics and

heat transfer

E: element of a system

$\mathrm{T}:$ temperature $\left({ }^{\circ} \mathrm{C}\right)$

Greek letters:

$\alpha$ : heat transfer coefficient $\left(\mathrm{W} \mathrm{m}^{-2} \mathrm{~K}^{-1}\right)$

$\epsilon_{\text {min }}:$ minimum accuracy demanded

$\epsilon_{\text {it }}$ : accuracy at current iteration
$\mathrm{U}$ : overall heat transfer coefficient $\left(\mathrm{W} \mathrm{m}^{-2} \mathrm{~K}^{-1}\right)$

t: time (s)

$\Delta \mathrm{t}$ : time step (s)

$\mathrm{x}, \mathrm{y}, \mathrm{z}$ : cartesian coordinates

$\Phi^{*}$ : guess value of a variable

$\Phi^{0}$ : variable value at previous instant 
Subscripts:

$1,2, \ldots \mathrm{n}$ : enumeration of the concerned quantity

r : room

amb: ambient temperature

wi: interior wall surface

exp: experimental

wo: exterior wall surface

num: numerical

\section{Acknowledgements}

This work has been partially funded by the "Ministerio de Ciencia e Innovación, Secretaría de Investigación", Spain (ref. ENE-2009-09496). 